\title{
A conceptual investigation of the ontological commensurability of spatial data infrastructures among different cultures
}

\author{
David J. Saab
}

Received: 1 June 2009 / Accepted: 28 September 2009/Published online: 21 November 2009

(C) Springer-Verlag 2009

\begin{abstract}
Humans think and communicate in very flexible and schematic ways, and a Spatial Data Infrastructure (SDI) for the Amazon and associated information system ontologies should reflect this flexibility and the adaptive nature of human cognition in order to achieve semantic interoperability. In this paper I offer a conceptual investigation of SDI and explore the nature of cultural schemas as expressions of indigenous ontologies and the challenges of semantic interoperability across cultures. Cultural schemas are, in essence, our ontologies, but they are markedly different than classical formal ontologies. They shape our ontological commitments to what exists in the world as well as the ways in which we approach and engage the world. And while they help structure our understanding of the world in which we are embedded, they are associative and flexible. They help to focus our attention to particular details of our experiences and give them salience, yet they cannot be simply reduced to a series of extracted features. They allow us to make meaning of the contextualized, cultural experience in which we are always immersed. An SDI is a shared social-technological-informational structure that, if it is to be useful and successful for sustainability in the Amazon, must incorporate and use indigenous cultural schemas. Indigenous communities must have the ability to contribute to the collection of geospatial data and their contributions recognized as legitimate forms of knowledge.
\end{abstract}

Communicated by: H.A. Babaie

SI: Spatial data infrastructures for the Amazon: a first step towards a Global Forest Information System

\section{J. Saab $(\bowtie)$}

College of Information Sciences and Technology,

The Pennsylvania State University,

University Park, PA, USA

e-mail: dsaab@ist.psu.edu
In order for the SDI to work, it must recognize the larger cultural landscape to which cultural schemas can connect to the ready-to-hand elements of salient cultural experiences.

Keywords Amazon · Cultural schemas · Culture · Heidegger · Indigenous · Interoperability · Ontologies · SDI $\cdot$ Semantics $\cdot$ Sustainability

\section{Introduction}

Spatial Data Infrastructure (SDI) is a common informational framework that provides a data structure using a standardized protocol and that allows organizations and institutions to share spatial information using information systems technologies. The sharing of data enables users to save resources, time and effort by acquiring new datasets collected by others. A common, open data format facilitates interoperability among information systems in use by various usersindividuals, agencies, institutions, governments, etc. Data standardization for interoperability is a common solution to technology-based problems of information sharing (Fonseca and Martin 2005; Smith 2003). Ensuring that our machines are speaking the same language, so to speak, and can thereby exchange data is a pragmatic necessity, which is why SDI initiatives often focus on creating common data models and protocols (Craglia et al. 2008; Fonseca and Martin 2005; Smith 2003).

SDI, however, is much more than data and goes far beyond surveying and mapping or exchanging mapping data; it provides an environment within which people, organizations, or nations interact with technologies to foster activities for using, managing and producing geographic data (Rajabifard and Williamson 2001). Negotiating the standards for SDI requires people with differing interests 
coming together to agree upon the types and classes of data for collection, the intended use of information, and sociotechnological mechanisms for sharing information. It is as much the social and institutional structures and processes involved in the sharing of data and information as it is the technological compatibility needed to do so. SDI is an initiative intended to create an environment in which all stakeholders can co-operate with each other and interact with technology, to better achieve their respective objectives at different political/administrative levels.

The workshop on SDI for the Amazon ${ }^{1}$ expanded the purpose of SDI to include dissemination of data to support sustainable development policies in Amazonia among scientists and communities in all stages and levels of environmental policy making (Davis et al. 2009). This includes scientists from a variety of domains, people who exploit the Amazon ecosystem in order to provide for themselves economically, as well as indigenous cultural communities who have extensive or traditional knowledge about their environments and who would be just as affected by the environmental policies developed. A significant challenge, however, is that these diverse sources and perspectives have the potential to create a richness of data that the SDI becomes overloaded with information and detail. There needs to be mechanisms or processes that allow for semantically bridging the ontological gaps between these diverse groups of information contributors. We must devise ways to filter data and translate concepts, ideas and details that have been constructed by scientists to make them accessible to the common citizen (Davis et al. 2009). Though the literature on SDI for the Amazon is limited (Câmara et al. 2006), it is easy to understand the logic behind this concern, where the richness of information about Amazonia - its biodiversity, its size, and the large number of cultures that interact with or within it - make the amount of information potentially contained within the SDI subject to a case of information overload.

The challenge of informational diversity is commonly addressed by information scientists through the building of formal ontologies - artifacts that provide a common dictionary of terms and definitions within a taxonomical framework - for knowledge representation. Formal ontologies are info-computational artifacts most commonly constructed using logical formalisms and predicate logic, which provide a consistent structure to information within an information system (Chandrasekaran et al. 1999; Gruber 1993; Guarino 1998; Smith 1995, 2003; Smith et al. 2005). These ontologies facilitate the sharing of data,

\footnotetext{
${ }^{1}$ Workshop on SDI for the Amazon, Rio de Janiero, Brazil, December 8-10, 2008. More information at: http://www.personal.psu.edu/fuf1/ SDI for the Amazon/Workshop $\% 20$ SDI\%20for $\% 20$ the $\% 20$ Amazon. $\mathrm{htm} \overline{\mathrm{l}}$
}

information, and knowledge among information-systems within communities.

The issue of SDI creation and use is not a matter simply of formal logical structuring of data, but rather is fundamentally an issue of ontology integration. The difficulty often (not) faced by information scientists and others is that the ontological commitments of different groups of people result in ontologies that are fundamentally different at the conceptual level and translating between them is not simply a matter of vocabulary matching. The translation of concepts is necessary, however, for semantic interoperability. While it is possible to impose a Newspeak solution (Fonseca and Martin 2005; Smith 2003), which embeds a so-called realist position and which requires everyone to conform to a common standardized ontology if they wish to participate, there are inherent problems with this approach. The first issue is that a formal ontology is unlikely to be able to capture the complexity of perspectives held by different scientific domains, or even the diversity of a single domain like geography, without logical contradictions. Formal ontologies are useful computational artifacts, but they also decontextualize and crystallize the concepts. In order to remain semantic, concepts require context (Saab and Fonseca 2008). A second issue is that the selection of the common ontology might be the product of social or political power and may or may not be the most applicable or effective ontology to use. A change in the socio-political power structure could result in a new Newspeak solution, with a different common ontology and differing information requirements, leading to conceptual and data gaps in previous and/or future SDIs. Conforming to a formal ontology that is not your own requires greater cognitive effort that some communities might not willingly extend. Their lack of involvement could affect the success of potential solutions to the sustainability problem identified by Davis et al. (2009). The Newspeak "solution" becomes a self-imposed limitation on what information is privileged and what is excluded, and it doesn't leverage the diversity of perspectives available or perhaps inherently valuable for devising solutions or encouraging coordinated involvement.

The challenge issued by Davis et al. of translating concepts between the specialized domains of scientists and the folk semantics of the common citizen is one that rests, I believe, on the understanding of culture. More specifically, the translation challenge rests upon the identification, representation and expression of diverse ontological commitments of the scientists, specialists and common folk such that we can incorporate them into a technological and informational system that allows users to navigate among sets of concepts familiar to and recognizable by them. In this paper, I will explore this challenge of ontology integration not as a pragmatic issue, per se, with clear 
solutions to be offered, but rather from a critical perspective that seeks to offer insights into the nature of creating SDIs as a process of ontology integration in which different groups and cultures have created their own legitimate forms of meaning and understanding for their environment (Rosaldo 1993; Watson-Verran and Turnbull 1995; Wilson 1998; Saab 2003). Such a focus shifts our research perspective from the classical notion of ontology as category disambiguation of classes and instances (i.e., formal ontologies) towards a conceptualization of ontology as complex conceptual networks and emergent cultural phenomenon (i.e., cultural schemas).

This distinction between ontologies-as-cultural-schemas and ontologies-as-logical-formalisms is fundamental to the perspectives, arguments and discussions offered in this paper. The latter are objectifications extracted from context, while the former are non-objective and contextual. I do not make the claim that ontologies can't be represented formally, but rather that formal ontologies comprised of logical formalisms are too rigid. Formal ontologies assume a so-called realism (Smith 2003) that fosters an objective rather than phenomenal perspective, which allow them to disregard context. They are unable to accommodate contradictory information because they are structured as logical formalisms. In contrast, schemas are constantly adapting but this does not mean that they are constantly (or significantly) changing on a cultural level. The intrapersonal schemas that are shared as cultural schemas change more slowly than any particular individual's schemas by virtue of their sharedness. A consensus has to evolve with respect to their alteration among a larger group of people, which imparts stability to cultural schemas. Making a shift from understanding and using formal ontologies to understanding and using cultural schemas has significant potential benefits for constructing ontologies for information systems that facilitate semantic interoperability.

I will discuss in the next section the nature of ontologies and their relationship to semantics and culture. How culture shapes semantics is the focal point of the next section on ontological challenges for semantic interoperability. In the following section, I will delve into much more detail with respect to culture, defining it as an emergent phenomenon that arises from the interplay of intrapersonal schemas and extrapersonal structures. There I describe the reasons why cultural schemas are essential to semantics and understanding and why lexical representations devoid of cultural schemas are inadequate ontologically. I will also introduce Heideggerian ontology and reveal its parallels to the idea of cultural schemas and the human experience, which holds lessons for our construction of SDIs and the formal ontologies for our information systems. Finally, I introduce examples indigenous ontologies and their geospatial conceptualizations, and I discuss their contextual implications in terms of ethnophysiography, cultural schemas, variability and adaptability and the idea of inter- and intracultural schemas. I conclude with a call for integrating cultural schemas into SDI and for establishing a phenomenological footing for our information systems' ontologies.

\section{Challenges for interoperability}

The construction of formal ontologies by information scientists is an attempt to overcome the Tower of Babel problem by providing a common dictionary of terms and definitions within a taxonomical (i.e., relationship) framework for knowledge representation that can be shared by different information-systems communities (Fonseca and Martin 2005; Smith 2003). However, theories of being, of what exists, are not defined by a common vocabulary, rather they are dependent upon particular perspectives and ways of understanding the world in which we are immersed. What exists is dependent upon our cultural schemas. Without an understanding of the perspective from which the geospatial data or information is offered (i.e., its ontology), the semantic issues become nearly impossible to overcome in such a rich and diverse information environment.

The creation of an SDI is necessarily a collaborative activity, thus also a shared activity of meaning making and thereby cultural. An SDI encompasses the policies, technologies, standards and human resources necessary for the effective collection, management, access, delivery and utilization of geospatial data for a specific jurisdiction or community (Rajabifard et al. 2002). There are many perspectives that are incorporated into an SDI: ecological, economic, infrastructural, scientific, etc. The SDI for the Amazon workshop report made clear that any successful effort towards sustainability must include a variety of people and communities - not only the structured scientific and governmental data, but also volunteered geographic information (VGI) that involves the use of social mediaGoogle Earth layers, mashups, blogs, wikis, etc. (Davis et al. 2009). The difficulty in handling the variety of geospatial data that may be generated is not simply a question of language translation; it has just as much to do with conceptual worldviews and the ontologies people hold as their cultural schemas. The social dimensions of the SDI ensemble require us to examine more closely, and integrate if possible, the experiential realities of place, not simply privilege 'space' and 'time', which serve as useful abstract conceptualizations for science (Casey 1996).

For example, Forero Larrañaga (1999) explains that the Tukanoans have no conceptualization of "rainforest." For them it is not an entity and they would never refer to themselves as living in one. They refer to their collection of territories as "the world," which is integral to their creation 
mythology, their social organization, and management of their ecosystem. "The world" and "rainforest" are not equivalent concepts, even in the bounded context of the Tukanoan territory. The substituting of "rainforest" for "the world" in any information environment, especially if that substitution becomes the basis for policy making regarding environmental management, transforms the issue from one of ontology and semantics to one of political power. We will discuss this and other indigenous geospatial conceptualizations in more detail below.

We recognize that different domains (i.e., cultures) can have different perspectives about a particular extrapersonal structure, and we are willing to accommodate such diversity generally. We simply prefer to think of our own cultural schemas as realist, privileged above others because of the assumed superiority of our epistemological methodsindigenous ontologies and epistemologies are regarded as cultural traditions while Western culture produces science (Stanner 1987). Whatever justification we use for establishing that privilege does not negate the fact that we are one culture among many, nor that each culture has its own ways of legitimizing meaning and handling the semantics of its discourse (Gupta and Ferguson 1997; Saab 2003). Recognizing that there exist different ontologies and different epistemologies among different cultures is not an antirealist position; rather it is a transcendence of the realist/ anti-realist dichotomy. It is relativist to the extent that legitimizes the existence of diverse cultural perspectives, but it is not a chaotic relativism. The cultural schemas we develop and employ have a stabilizing influence upon members of a culture and enable them to co-create shared understanding of the world.

People from different cultures can look at the same extrapersonal structure and derive completely different meanings from it. It is the interplay of the intrapersonal and extrapersonal that provides the contextual frame for proper interpretation of semantics. We engage in such interplay effortlessly in human-to-human interactions, as all experience is culturally contextualized - we are always situated within a context, and our cultural schemas shape our understanding of it - we are forever being-in-the-world. When we decontextualize semantics by representing them as syntactically arranged lexical units and mereological relationships within a formal ontology, we transform the intrapersonal schema into an extrapersonal structure. The act of representing externalizes the schema and thereby eliminates its dynamic and emergent nature by excluding the essential intrapersonal cultural elements that allow for the emergence of meaning. Our representations metaphorically crystallize it, making it rigid and inflexible. If we want to achieve semantic interoperability among our informational and computational systems and our SDIs, we can't exclude the cultural schemas that are essential to the emergence of meaning and provide for us the complex connections to the larger cultural conceptual landscape.

\section{Ontologies, semantics and culture}

Ontologies and semantics are intimately linked. Uschold (2003) describes the semantic continuum with implicit semantics that exist as part of a shared human consensus to a formal semantics for machines that processes and uses semantics at runtime, as depicted below (Fig. 1):

As Uschold has modeled it, the further one moves away from shared human consensus, the less information one has about the context to use in making meaning. Whereas most work on information systems ontologies is focused on transforming text descriptions into logical formalisms for machines, in this paper I want to focus on the implicit qualities of ontologies as shared human consensus. To achieve semantic interoperability, we must devise ways to include and represent the implicit semantics that allows us to communicate with other people. Implicit semantics relies upon shared ontology, contextualized in experience, in order for information to be meaningful. For true semantic interoperability to occur among diverse information systems, within or across domains, information must be contextualized rather than objectified as part of a computational artifact. But attempting to provide a precise description for every possible context and transforming them into logical formalisms is an impossible task, if not a fool's errand. Even if it were possible, our formal ontologies would be a crystallization of an emergent experience, and brittle, such that attempting to alter them based on a new understanding, or new knowledge, or attempting to merge ontologies, would almost always results in breaking them.

One might argue that incorporating multiple ontologies containing diverse cultural perspectives can circumvent the objectification problem, but having multiple formal ontologies doesn't eliminate the problem of semantic interoperability, it compounds it-there is no mechanism for blending these multiple ontologies or accommodating

Fig. 1 Uschold's semantic continuum

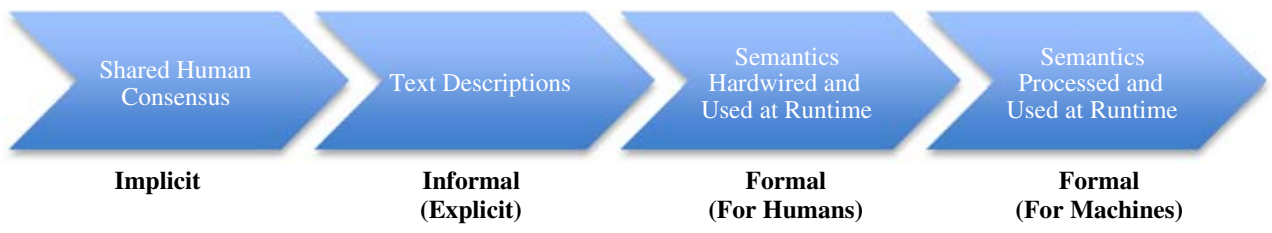


contradictory information contained within them. If one were to construct an automated reasoning process using inferences, any inferences that are constructed will have to privilege one ontology over another, especially in the case of contradictory information, in which case why bother to have multiple ontologies in the first place?

To ground this notion of contextualization, I draw upon Heidegger's (1927) notion of being-in-the-world in which each of us is immersed in and never separate from experiential context. This context is the ever-present background that shapes our semantic and ontological commitments to the world around us-helps us make meaning of what we perceive to exist. Moreover, we are always being-in-becoming, experiencing the world as emergent-dynamic, contextualized and with a personal historical perspective. In this way, Heidegger eschews the classical ontology of category disambiguation in favor of ontology as an emergent phenomenon. It is this notion of being-in-becoming that also allows us to introduce the notion of culture to the study of ontology in information science and the creation of SDI.

The notion of culture as described by cultural anthropologists (D'Andrade 1995; Strauss and Quinn 1997) closely parallels the notions of being-in-the-world and being-in-becoming. Culture emerges through the interplay of intrapersonal cognitive structures and extrapersonal structures in the world. Culture is a phenomenon integral to our experience and one that shapes our ontological commitments to the world around us. What we presume to exist and the meaning that we make of the world is dependent upon our cultural schemas and experiences. What information is deemed important, how that information is modeled and represented (e.g., through language or images or art), and how it is presented and displayed is dependent upon the cultural context in which the information system exists and the cultural schemas shared by those developing and using the system. Culture ${ }^{2}$ helps to focus our attention on and make meaning of relevant extrapersonal structures and their qualities and dimensions that comprise the context and background of the world. We are always immersed in a cultural experience.

\footnotetext{
$\overline{2}$ This characterization of culture is somewhat at odds with our linguistic conventions, as will be explained in more detail in the subsequent paragraphs. In common speech, we refer to culture as if it were an entity separate and apart from human cognition. I can refer to Western culture, or Brazilian culture, or indigenous cultures, and these would have meaning for us. However, as we define culture here, it is an emergent phenomenon, not some thing that exists independently of human experience. When I use the word, culture, throughout this paper, I refer to an emergent phenomenon and not to an objective entity. When I use the word, cultures, I refer to groups of people identifiable by their shared intrapersonal schemas.
}

Schemas: the intrapersonal dimensions of culture

In cognitive science, connectionist theory posits the human conceptual system as a network composed of a large number of units joined together in a pattern of connections (Rumelhart and McClelland 1986). Cognitive anthropologists and educational psychologists refer to these patterns of connections as schemas (Anderson et al. 1984; D'Andrade 1995; P. M. Davis 1991; Strauss and Quinn 1997). Strauss and Quinn (1997, p. 6) define schemas as "networks of strongly connected cognitive elements that represent the generic concepts stored in memory". D'Andrade (1995, p. 140) expands on this concept and describes schemas as "flexible configurations, mirroring the regularities of experience, providing automatic completion of missing components, automatically generalizing from the past, but also continually in modification, continually adapting to reflect the current state of affairs". Describing them as 'flexible, mirrored configurations' implies that schemas are entities within cognition that are comprised of several elements that have both structural and representational qualities. Schemas are not the individual elements, but rather strongly connected clusters of elements of experience within cognition. Elements of experience are clustered in cognition, which increases efficiency, because they are clustered in our lived experiences. Simply mentioning the name of something is often enough to activate schemas associated with it. Schemas help to fill in the ambiguous or missing information because the associated neurons and cognitive elements are more likely to be activated by the initial stimuli.

Schemas - these strongly connected networks of cognitive elements - are powerful processors of experience, help with pattern completion, and promote cognitive efficiency. They serve to both inform and constrain our understanding of experience. People recall schematically embedded information more quickly and more accurately (DiMaggio 1997). In fact, schemas hold such sway in our cognition that people may falsely recall schematically embedded events that did not occur. They are more likely to recognize information embedded in existing schemas because of their repeated activation. This repeated activation evokes expectations within cognition, and the easy recognition of contradictory or challenging information that do not conform to those expectations formed as part of the existing schemas. Information that is orthogonal to existing schematic structures, that doesn't acquire salience through the repeated activation of schemas and the creation of associated expectations, is much less likely to be noticed or recalled. Because of their functionality in pattern completion, schemas function, in some sense, as flexible filters of experience, enabling us to attend to its salient features while filtering out the non-salient. 
Schemas' relationship to culture

Schemas are cognitive entities. They help us to process information. It would be inaccurate to say that schemas are separable from culture, for that would imply that culture consists solely of the external world structures outside the individual. Schemas are intrapersonal (cognitive) structures. The objects or events that are manifest outside individual cognition, the entities in the external world, are extrapersonal structures (Strauss and Quinn 1997, p. 6). Culture consists of the interplay between the intrapersonal cognitive structures and extrapersonal structures such as systems of signs, infrastructure, environment, social interaction, and so on. The intrapersonal and the extrapersonal are different and distinct, but closely interconnected. They are not isolated from one another, rather separated by a permeable boundary. Culture encompasses both intrapersonal and extrapersonal structures and emerges from the interplay between them. It is through this interplay that we can see that some of the intrapersonal cognitive structures called schemas are shared.

\section{Shared schemas as cultural schemas}

The sharing of schemas does not require people to have the same experiences at the exact same time and place, rather that they experience the same general patterns. As agents in the world, we organize our experiences in ways that ensure ease of communication, coordination of activities, and collaborative interaction. Because we organize our experiences in particular ways, people in the same social environment will indeed experience many of the same typical patterns. In experiencing the same general patterns, people will come to share the same common understandings and exhibit similar emotional and motivational responses and behaviors. However, because we are also individuals, there can be differences in the feelings and motivations evoked by the schemas we hold. "The learner's emotions and consequent motivations can affect how strongly the features of those events become associated in memory" (Strauss and Quinn 1997, p. 133). Individuals will engage the external world structures and experience the same general patterns. Similar stimuli and experiences will activate similar schemas. It is in that sense we consider them to be shared schemas. It's their quality of sharedness that makes them a dimension of the cultural.

Schemas also have other qualities that make them a dimension of the cultural. Some schemas are durable. Repeated exposure to patterns of behavior strengthens the networks of connections among the cognitive elements. Some schemas show historical durability. They are passed along from one generation to the next. Some schemas show applicability across contexts. We draw upon them to help us make sense of new and unfamiliar experiences. Some schemas exhibit motivational force. Such motivation is imparted through learning, explicitly and implicitly, strengthening the emotional connections among the cognitive elements. Schemas are not rigid and inflexible. They are adaptable, sometimes resulting in the strengthening of existing schemas, sometimes in their weakening in the face of new experience.

We share the intrapersonal dimensions of culture when we interact with others. In sharing these intrapersonal dimensions, schemas are activated. Activation evokes meanings, interpretations, thoughts, and feelings. We make meaning of our experience. The cultural meaning of a thing, which is distinct from the personal cognitive meaning, is the typical interpretation evoked through life experience, with the acknowledgement that a different interpretation could be evoked in people with different characteristic life experiences. In some cases our experience is intracultural, where we share a similar cultural frame. In other cases our experience is intercultural, where we are attempting to share different cultural frames. The meanings evoked by one person in relation to a particular extrapersonal structure may not be the same as those evoked in another. In fact, the meanings evoked may not be the same within the same person at different times, for they may experience schema-altering encounters in the interim. The ways in which we share these intrapersonal dimensions of culture makes each person a junction point for an infinite number of partially overlapping cultures.

Contextualization and emergent experience are not synonymous with chaos, however. Common and stable meaning persists because cultural schemas provide that stability and facilitate common/shared understanding. We don't enter every new situation or moment as a blank slate, experiencing the world for the first time (Talmy 2001). Cultural schemas are the ontological structures that provide stability and facilitate semantics with respect to our experiences. They are what enable stability and persistence of meaning, because they allow us to adapt prior experiential understanding to new contexts through the recognition of what Heidegger refers to as ready-to-hand elements of experience.

\section{Culture as mediator for what is ready-to-hand}

Reconceptualizing ontologies as cultural schemas is better explained using a Heideggerian ontological perspective rather than an Aristotelian one. For Heidegger (1927), the basic state of Dasein - man's being (literally, "there being") - is understanding, making sense, making meaning of the world in which he is embedded. Immersion in the world is an inescapable fact of human existence. The world and the meaning we make of the world are inextricably linked through our experience within the world. Our experience of 
the world is also always cultural-what we recognize as salient is dependent upon the conceptual fore-structures (i.e., intrapersonal schemas) we employ in making sense of our contextualized experience (i.e., the encountering of extrapersonal structures).

Another inescapable fact of our existence is temporality. We are always falling into the next moment with an accompanying directionality of our conceptual forestructures. In other words, we have expectations as we move temporally through the world. In coping with our everyday existence we encounter two basic modes of intentionality according to Heidegger: (1) an objective intentionality corresponding to the present-at-hand, and (2) a deictic intentionality responding to the ready-to-hand (Agre 1988). The expectations generated by our forestructures have a duality about them. They are able to accommodate the holism of our experience to some degree by what Heidegger describes as ready-to-hand, as well as the present-at-hand elements, features, entities and phenomena that become the focus of our attention at any given moment.

We must not mistake, however, the present-at-hand or the ready-to-hand for objectivity. For Heidegger, entities reveal themselves as already imbued with a purpose or 'assignment', as having an assigned role to play (Cerbone 2008). 'Assignment' makes them more than mere 'things', and thus context-sensitive and non-objectifiable, per se. (The same can be said for geography and geographic entities, which will illustrate through examples of indigenous geospatial ontologies in the next section.) Our embeddedness and embodiment preclude a state of objectivity, per se. Ready-to-handedness is the "perception of the inherently interested kind built into any kind of contextsensitive, intelligent behaviour" (Christensen 2007). Readyto-handedness is a form of phenomenal holism that describes the salient background features and elements of an engaged, embodied and embedded subject by virtue of what he recognizes as existing within that context and the possibilities that can emerge from those features and elements in that context. Experiencing this phenomenal holism does not mean we are unable to identify unique entities or things in our environment. We can and doHeidegger describes these things as presence-at-hand. We must be careful, however, not to mistake a presence-athand as objective and separable from its readiness-to-hand qualities. It is the interaction of the present-at-hand and the ready-to-hand that provides for the meaningfulness, or the semantics, of our experience.

What is present-at-hand is the extrapersonal structure that, through abstraction, is momentarily salient and becomes the focus of our attention through the activation of an intrapersonal schema. That momentary focus constrains our experience in terms of its directionality because we are attending to the salient elements of the entity or phenomenon we experience. It limits the possibilities of what is ready-to-hand. But we continue falling, and we attend to what is ready-to-hand, and transform those elements into salient focus, making them present-to-hand. In other words, each constraining focus opens up a limited set of possibilities, which in turn constrains then opens another set of possibilities in an unending process of emergent experience- a hermeneutic circle. Our forestructures shape our falling such that the world we experience can be described as a cultural landscape. Our cultural landscapes have coherence because they have structure that derives from our cultural schemas, which encompass what becomes present-at-hand within the wider landscape of the ready-to-hand.

Applying Heideggerian ontology to artificial intelligence, Freeman (1991) uses the metaphor of an attractor landscape, which is useful to our discussion here. It is not the particular elements that activate our schemas, but rather their salience - "the significance of the stimulus," (Freeman 1995). Freeman wants us to imagine a conceptual landscape as if it were a physical landscape with craters. These craters represent concepts, with salient, permeable boundaries that form the rim of the crater. The crater is what Freeman refers to as an attractor. And the basin (lowest point) of the crater is a basin attractor, which is the conceptual place that it takes minimal energy for our attention to flow. The path of our attention from rim to basin is what we refer to as the activation of an intrapersonal schema.

Now imagine that these craters exist in relation to one another, forming a complex network of basins in the landscape, i.e., an attractor landscape. When we view the attractor landscape, we see a vast network of basins, clusters of basins, basins within basins, and basins overlapping basins. Moreover, this landscape of basins lies upon a malleable surface that allows for changes in the landscape based on newly lived experience. Because the entire complex network landscape of craters is interlinked, localized changes arising from experience will have an effect on the structure and strength of the entire network. The attractor landscape metaphor reflects the notion that concepts (i.e., craters) don't exist in isolation but rather as part of the network of schemas we develop through our lived and embodied experiences.

Dreyfus (2007) notes that Freeman's research indicates that there are "no linear causal connections between world and brain nor a fixed library of representations, but where...significance that is directly displayed in the world...is continually enriched." In constructing an SDI, we tend to focus on informational structures as a "fixed library of representations', much as we try to structure ontologies using strict logical formalisms. What I have argued here is that constructing an SDI is tied to ontology 
elicitation, which is grounded in the shared cultural schemas of a group of people, must be considered as through the lens of 'structural coupling' (Winograd \& Flores 1987), and which we can better understand from a Heideggerian perspective using the concepts of ready-tohand and present-at-hand.

Another metaphor that might be useful here is the relationship between wave and particle in quantum physics. Let us think of our cultural landscape as a wave, as a phenomenon that can only be grasped as temporal and in continual flux. When we try to focus upon the wave, it collapses into a particle. The quanta exhibit the qualities of both waves and particles. Our ontologies, our cultural schemas, are similar. They exist within a continually emerging experience, as if they were patterns of waves. The segmentation of ontologies into semantic segments is similar to a series of particles that results from the focus of our attention on what is present-at-hand based on the limited possibilities of what is ready-to-hand. Every interaction we have with the wave alters it, just like every contextualized experience we have alters our intrapersonal schemas. The difficulty we have is that our semantics are lexically expressed - a syntactically sequenced series of particles. If we want to achieve semantic interoperability for an SDI that serves not only the dominant culture but also the multiplicity of cultures, we must devise ways of including the 'waves' of the cultural landscapes.

\section{Indigenous geospatial ontologies}

In this section, I will explore some of the implications for SDIs that incorporate indigenous geospatial ontologies, as would an SDI for the Amazon. I will use particular examples from several cultures to illustrate some of the challenges that emerge from the inclusion of indigenous ontologies and perspectives into a socio-technicalinformational ensemble like an SDI. These examples will illustrate how merging ontologies of different cultures within an SDI is not simply a matter of vocabulary matching or alignment of categorical hierarchies. They will serve to reinforce the notion that cultural schemas serve as facilitators of semantics within a cultural group. If the information regarding space stored in an SDI is to be meaningful (the present-at-hand particles), especially if it includes VGI, we need to be able to access or incorporate the cultural schemas upon which that information is based (the ready-to-hand waves). The examples offered below are not meant to provide definitive and pragmatic solutions to intercultural integration for an SDI, but to highlight some of the fundamental issues involved and to support the notion that whatever representations are created to represent geospatial information must accommodate the cultural schemas of the users of that SDI-indigenous users in the case of an Amazon SDI.

Ethnophysiographies: categories and vocabularies

'Ethnophysiography' is a term coined by Mark and Turk to examine the similarities and differences in conceptualizations of landscape held by different language and/or cultural groups and how those groups categorize and name the variety of features in their landscapes (Mark and Turk 2003a, b). Mark and Turk note the difficulties of integrating indigenous knowledge with Western 'realism', and moved away from an earlier unfruitful approach (Mark and Turk 2003b) towards an exploration of a phenomenological perspective in ethnophysiography (Mark et al. 2007) in which the notion of lived experience of the inhabitants became central. A phenomenological approach connects more strongly the linguistic term with the ontological concept, for it explores the relationships between features and how the language speaker understands those features. In many cases, with their research on Yindjibarndi (an Australian Aboriginal language) ethnophysiography, the speakers would spontaneously make references to spiritual concepts (Mark et al. 2007, pp. 13-14). Ethnophysiographic research among the Yindjibarndi reveal that the conceptualizations (i.e., ontology) of water in the desert landscape "is a matter of categorical predication...otherwise similar entities that differ only in being permanent or temporary apparently are considered to be different kinds of things and referred to using different terms" (p. 16).

The difficulty with the linguistic expressions of geospatial categories is that the lived experience of the speakers reflects not only features within their environments, but also their lived relationships with those environments. The phenomenological approach later adopted by Mark and Turk allowed them to speculate as to some of the causes of difference in categorizations among speakers of different languages: topography, climate, vegetation, lifestyle/traditional economy, religious/spiritual beliefs, historical factors, language grammar, and place name structures (Mark et al. 2007). Each of these potential differences speaks to the lived experience of the people within their social and physical environments. Something similar is reflected in Majid et al.'s observation that people living in less-constructed landscapes use more nonegocentric navigation directions, e.g., absolute directions like north, south, east, west (Burenhult and Levinson 2008; Majid et al. 2004). This non-egocentric direction characteristic exists also in the Marshallese language, where the preferred way of indicating direction is to indicate north (eañ), south (rõk), east (rear), west (rãlik), or to indicate oceanside (lik) or lagoonside (aar). Left and right, which 
are egocentric directions common in English, were rarely used in a Marshallese context. ${ }^{3}$

Above we mentioned the case of the Tukanoans of the Amazon whose conceptualization of their landscape was more closely associated with 'world' than with 'rainforest'. In fact, the Tukanoans have no word for 'rainforest'. A similar example can be cited with respect to the concept of wato in the Marshall Islands, for which there is no precise English equivalent. Wato embodies a complex network of conceptualizations related to a very specific context - in the Marshall Islands, inhabited by a Micronesian cultural group, in a country comprised of coral atolls and islets. The word wato refers to a tract of land of variable width that stretches from lagoon to ocean. But it is more than simply a segmentation of a physical landscape - it evokes notions of familial structure, rights of inheritance within a matrilineal culture, the ability to travel between islands and atolls for resources that are extremely scarce and easily depleted, and the responsibilities one has with respect to family, descendents and resource management. There exists no rivers or other waterways, nor any mountains or other types of mounds in the Marshall Islands, and therefore none within any wato. In one sense, wato has an English equivalent of tract, but a tract in a very specific sense. A wato could not be a partial tract that was carved out from another wato without access to either lagoon or ocean. It can only be a band of land that spans the entire width of the island. All land in the Marshall Islands (approximately 70 sq. mi. total) is divided in this manner, without exception. Matching tract with wato in a computational ontology would be a misfit. Indeed, it would be difficult, if not impossible to find a single equivalent for wato in English, in which case our computational ontology fails miserably.

Does wato have an equivalent abstract form in a formal ontology? Wato is a sub-structural category of island, but an island specific to a coral atoll. It has relationships with the lagoon and the ocean as well as the other wato (up to two in number) that border it. It is a fiat object, constructed by cultural convention and may belie whatever natural discontinuities exist; and its boundaries are determined roughly and according to mutual agreement rather than specific or technical geographic surveys using a Cartesian coordinate system. There is no uncertainty (within the bounds of mutual agreement) as to where the border between two wato exists, unlike the nebulous border that separates a

\footnotetext{
$\overline{3}$ The knowledge of Marshallese language and culture derives from my personal experience of eight years spent in the outer islands and urban centers of the Marshall Islands. I have a Native Fluency rating in Marshallese language conferred by Alfred Capelle, author of the Marshallese-English Dictionary. My knowledge of the language and culture is often noted as being deeper than native Marshall Islanders my age, because of the extensive amounts of time I spent talking with and learning from the elders in the villages I lived.
}

peninsula from the mainland. Conceptually, wato describes a division of land that is bordered on at least two, possibly three, sides by water; existing only relation to those bodies of water and other wato and intersecting none of them.

Does understanding the (formal) ontological fundamentals of wato help us in determining what it is or in finding its ontological equivalent in another language or culture? I suggest that it isn't very helpful, for two reasons: 1) it is a single instance, semantically expressed, for which generalizing to the ontological level of analysis entails the loss of meaning; and 2) it is a concept very specific to a particular culture and environment, and for which an equivalent in another culture is unlikely to exist. Developing any ontology is problematic insofar as persons with a particular viewpoint who are immersed in a particular culture always will have constructed it. Facilitating an ontological model from a particular group of people is necessarily facilitating a conceptual worldview from that group, and as such, is a facilitation of their cultural and cognitive schemas regarding an ontological 'reality'. Even the practice of using lattices as ontological frameworks (Sowa 1999) to generate a more flexible hierarchy of categories is dependent upon the fact that someone must choose which categorical distinctions are 'appropriate' for incorporation into the lattice.

As these examples have shown, categories and vocabularies are intimately linked to the lived experience of a people with their environment. The earlier approaches of ethnophysiography in which the researchers tried to discern and match the categorical structures of different cultures gave way to a phenomenological approach that took as its starting point the idea that people are embedded in the world, that categories and vocabularies people use to describe their environments are best understood in context rather than as abstracted taxonomical structures. The idea that categories and vocabularies of space cannot be simply translated across linguistic boundaries, and that a phenomenological approach is better suited to understanding them, leads to the ontological and conceptual dimensions of experience and the idea that understanding cultural schemas is an important component in understanding the ontologies of other cultures.

Cultural schemas: beyond categories and vocabularies

Australian Aboriginal geographies provide a high-contrast example of the difficulties of representing geospatial ontologies within an SDI. Ethnographers and popular writers have described Aboriginal conceptualizations of their geography as a series of 'songlines' that are manifestations of 'The Dreaming' (Bateson 1990; Carrick ca. 1980; Lawlor 1991; Stanner 1987). Indeed, Stanner explains that 'The Dreaming' is the phrase used to express Tjukurrpa by Aboriginal Australians in English. Tjukurrpa is a complex cultural schema described by Cane (2002) as 
more appropriately reflecting the concept of 'the Law'. ${ }^{4}$ It encapsulates much more than the Western cultural conceptualization of law, however. Tjukurrpa "incorporates elements of fear, power, complexity, reason and authority, but also conveys something universal and metaphysical" (Cane 2002 , p. 81). It is more spiritual than judicial, where spiritual beings are described as belonging to 'the Law' and geography is seen as part of 'the Law', ceremonial acts are conducted as expressions of 'the Law', and senior holders of the Tjukurrpa are 'Law Men'. Physical features of the landscape might be described as 'Law' or might not be spoken of except in whispers (e.g., 'big Law'). Cane describes Tjukurrpa as a utilitarian framework having both personal and social dimensions:

It is almost a way of thinking or being. It provides an explanation of nature, establishes a social code, creates a basis for prestige and political status within the community, acts as a religious philosophy and forms a psychological basis (if not psychological controls) for life. The Tjukurrpa also establishes a political basis for defining and negotiating rights to land. Tjukurrpa is perhaps best described as an Aboriginal equivalent to the European concept of tradition. It is the conceptual vehicle through which people fulfil themselves, define their position in society and are guided through life. Spinifex adherence to the Tjukurrpa is both fundamental and mandatory...

It provides implicit prescriptions for environmental management, deals with consequences arising from catastrophes such as floods and fires, and caters for minor matters such as water conservation and site protection. Tjukurrpa explains the nature and creation of land forms and natural phenomena such as fire, wind and water. Such explanations carry with them a sense of greatness and mystique which instills respect and establishes protective mechanisms for particular geographic locations. Knowledge of Tjukurrpa in such circumstances creates a basis for power and prestige within Spinifex society.

Thus when Western Desert people talk about the Tjukurrpa in relation to sites and tracks, they are talking about all the social and political values and relationships of their society which those sites articulate as much as about the spiritual values of those locations. Site protection is not, therefore, so much about looking after

\footnotetext{
${ }^{4}$ Among the Spinifex People, one of the Western Desert peoples of Western Australia, who were also nuclear nomads for a time, like the Bikini and Rongelap peoples of the Marshall Islands who are still exiled from their ancestral homelands.
}

the physical character of a particular site but about protecting the Tjukurrpa-the spirituality of the location and the inherent social and political values that are linked to the land through Tjukurrpa that give society its functional order and provides members of that society a place an position within it. To damage a 'sacred site' is more than just damaging the fabric of that site or damage its spirituality, it is an attack on the intrinsic values of the society associated with that site. (pp. 82-83)

Tjukurrpa stories have variable meanings, locations and associations. These stories describe great marvels, explanations of how certain things were instituted for the first time, and reflect many of the cultural institutions of contemporary life (Stanner 1987). The marvels occurred and institutions manifested in geographic space, and recounting the stories trace paths in the landscape that embody the Tjukurrpa, and which have come to be known among non-Aboriginal peoples as 'songlines' (Lawlor 1991). Representations of Aboriginal geographic space reflect the paths that 'belong' to certain peoples. For example, the Bush Turkey Man (Wati Kipara) Tjukurrpa is seen as belonging to the Spinifex people although it originates in and traverses part of the 'territory' of the Pintupi People. The Wati Kipara Tjukurrpa as well as other Tjukurrpa represented pictorially "in terms of the Tjukurrpa associated with that country rather than in terms of distance or geographical perspective" (Cane 2002, p. 97).

The Wati Kipara Tjukurrpa recounts the travel of an old bustard that attempts to steal the world's fire and drown it in the ocean at Madura. Before he can drown the fire, his two sons take it and drag the 'Old Man' back to the Spinifex homelands, where he slowly dies. The sons distribute the fire, with great celebration, to all the inhabitants of the earth. There are a number of features in the landscape associated with the spirit of Wati Kipara and his sons-termite nests, salt lakes, escarpments, large rocks, cave, trees, and more. The Wati Kipara Tjukurrpa "involves excruciating physical punishment, murder, betrayal, sex, deceit and intrigue, but the details of these events remain secret and privy only to senior men." (Cane 2002, p. 87).

The Spinifex example highlights three challenges to the creation of an SDI based on a formal ontological and data structure. First, a central and essential concept of Aboriginal geographies-Tjukurrpa - is difficult to translate into another cultural context. There is no single parallel concept available in Western culture or in English. The translation requires a much more extensive explanation that includes a description of the cultural schemas used by Aboriginal peoplesobligatory social behavior, the value of knowledge, the associations with paths and features of the landscape, etc. Second, Aboriginal conceptualizations about their geography do not depend on 'space' as much as they depend on 'place'. 
The idea of measured distances, and therefore standardized representations, isn't an essential component in geographic representation. Much more important is the relationships among the landscape features and the collection of Tjukurrpa. Third, the Tjukurrpa stories are variable in terms of associations, locations and meanings. The variability of oral narratives in general reflects the adaptive nature of ontologies and cultural schemas to context.

Variability and adaptability

The narratives of the Apache illustrate the cultural schematicity and the inherent variability that are also reflected in the Aboriginal Tjukurrpa. Basso (1996) describes four types of indigenous narratives based on his ethnographic work with an Apache community in the southwestern United States-myths, which concern the time of creation and are used to instruct on the complex processes by which the world came into existence; historical tales, whose main purpose is to provoke the conscience and correct improper behavior; sagas, which are tales of recent history whose main purpose is to entertain; and gossip, which is storytelling of current or recent events. The narratives of Apache place-making are framed with an closing lines could be considered metaphorical boundaries, separating the morality tale from the general conversation. Oftentimes, simply expressing the opening line is sufficient to share the entire schema with others. The narratives evoke a particular physical setting in which the listeners can imaginatively situate themselves in relation to everything that happens - i.e., create a pictorial space in their mind:

\section{It happened at Big Cottonwood Trees Stand Here and} There.

Long ago, the Pimas and Apaches were fighting. The Pimas were carrying long clubs made from mesquite wood; they were also heavy and hard. Before dawn the Pimas arrived at Cibecue and attacked the Apaches there. The Pimas attacked while the Apaches were asleep. The Pimas killed the Apaches with their clubs. An old woman woke up. She heard the Apaches crying out. The old woman thought it was her son-in-law because he often picked on her daughter. The old woman cried out: "You pick on my child a lot. You should act pleasantly toward her." Because the old woman cried out, the Pimas learned where she was. The Pimas came running to the old woman's camp and killed her with their clubs. A young girl ran away from there and hid beneath some bushes. She alone survived.

It happened at Big Cottonwood Trees Stand Here and There.

(Basso 1996, p. 52)
On the surface, this narrative seems to be about an ancient battle between two cultural groups. But it is not used to evoke memories of history, per se. Rather, it is about proper behavior and the harmful consequences that may come to persons who overstep traditional role boundaries. Apache couples live in the camp of the bride's parents during the first year of marriage. During this year, the bride's mother may request that her son-in-law perform various tasks and she may also instruct and criticize him. $\mathrm{He}$ accepts this role and the instruction without question. Once a couple establishes a separate residence, however, the mother-in-law may properly interfere in her son-inlaw's affairs only at the request of her daughter. Women who do not abide by this arrangement and continue to criticize their sons-in-law imply that they are immature and irresponsible, which is a source of acute embarrassment for the young men and their wives. This tale, then, serves as a metaphor for appropriate social behavior: Even when meddling might seem to serve a useful purpose, it should be scrupulously avoided. The woman on whom this story centers failed to remember this and was instantly killed.

Apache are reminded of the tale every time they encounter the Big Cottonwood Trees. Non-Apache, who have never heard the tale, would simply have no idea as to the cultural significance of the grove of trees. They would have no reference for making meaning of this particular grove of cottonwood trees. For the Apache, however, the encounter or mention of the Big Cottonwood Trees evokes cultural schemas, in particular the social boundaries that prevent interference by family members.

We see that schemas associated with familial relationships, marriage, privacy, restraint, and so on, are conveyed through this tale. Among the Western Apache, morality tales are conceptualized as arrows piercing the mind of the recipient, sometimes striking with great precision and causing immediate, intensive reflection about his immoral behavior. Not only is the tale itself conceived of as a metaphorical event within haptic space (arrow flying across the distance to pierce the target), but also such tales among the Western Apache are tied to specific geographic locations. The association of these arrows to physical sites in the geographic landscape is significant because the places serve as a permanent reminder of proper conduct and the consequences of improper conduct. Building on the hunting metaphor, the Apache say that these places stalk them:

Even if we go far away from here to some big city, places around here keep stalking us. If you did wrong, you will hear the names and see the places in the mind. They keep on stalking you, even if you go across oceans. The names of all these places are good. They make you remember how to live right, so 


\section{you want to [re-place] yourself again. [Nick Thompson in (Basso 1996)]}

The worldview from which the narrative of Big Cottonwood Trees is drawn explicitly associates the physical geography to the members of the culture. The narrative may be flexible in terms of time, but requires a spatial anchor to be understood. The purpose of the Basso's ethnography is to portray the strong connections the Apache community has with their lands and how places of historical significance exert influence on the behavior of individuals and reinforce their identity as Apache.

The Apache narrative above is an historical tale, distinguished by an introductory and closing line that set them apart from other categories of tales. These Apache narratives are tied directly to places and specifically intended to evoke schemas of appropriate behavior, to reinforce cultural identity and connection to Apache land and its community's history. Simply mentioning the name of the particular place is sufficient to evoke the schemas related to appropriate behavior. But the mention of the place name evokes more than schemas related to behavior. Apache narratives require a spatial anchor, without which the story loses resonance. The spatial anchors are built into the name of the places. Apache place-names rarely form complete sentences, but the Apache language is rich with prefixes and suffixes that carry an extraordinary density of information. Basso offers a few examples (p. 46):

\section{Water Flows Down On A Succession Of Flat Rocks}

Tséé Biká' Tú Yaahilíné: Tséé (rock, stone) + Biká' (on top of it; a flattish object) + Tú (water) + Yaa(downward) + -hi- (linear succession of regularly repeated movements) + -lí- (it flows) + -né (the one).

\section{Water Flows Inward Under A Cottonwood Tree}

T'iis Bitl'áh Tú 'Olíné: T'iis (cottonwood tree) + Bitl'áh (below it, underneath it) + Tú (water) + 'O(inward) + -lí (it flows) + -né (the one).

\section{Line Of White Rocks Extends Up And Out}

Tséé Hadigaiyé: Tséé (rock, stone) + Ha- (up and out) + -di(extends in a line) + -gai- (white, whiteness) +-yé (the one).

These examples illustrate how thoroughly descriptive Apache place-names are. But they also enable Apache listeners to imagine in great detail how they appear, locating the narrated events in the physical settings where the events occurred. Place-names embed a particular spatial relationship between the individual and the geographic space. They provide situatedness to the individual's cognition-providing the specific visual perspective of where the individual must be located in space in order to see the named place.
There is a rich semantics to Apache place-names that are integral to the geographic space in which they exist and in which they can and should be viewed. The place-names are not only descriptive of the spatial experience, but also of cultural experience. The geography embeds the historical lessons upon which Apache social norms, cultural values and cultural assumptions are based. For an SDI to be optimally effective and meaningful for an Apache user, it must depict the culturally significant places from a situated perspective that is reflected in the name of the place.

Each of the narratives above has a different focus. The ethnographic accounts from which they originated were constructed with different contextual themes, with different explanatory purposes. Each of the narrative examples exists within a larger context, of both narrative and culture. They are but single examples in a myriad of tales that are shared among members of the respective cultures. Using connectionist metaphor, we could say each example is like the firing of a network of neurons that produces a gestalt- a complex of associated thoughts and feelings. This gestalt embodies an array of interconnected thoughts and feelings that are further interconnected and intermingled with a variety of other thoughts and feelings. They form a density of connections that are difficult to extricate from one another and, if linked together with other gestalts, form a complete network, a complete cultural worldview.

Inter- and intra-cultural schemas

Cultural groups don't exist in isolation, and they must facilitate adaptation or die if one adopts an evolutionary perspective. The definition of culture offered in this paper - as an emergent phenomenon arising from the interaction of intrapersonal schemas and extrapersonal structures -implies that any set of shared cultural schemas can be said to constitute a culture. The logical extension of this implication is that individuals become junction points for an infinite series of overlapping cultures. At a macro level, we identify cultural groups in our world-Western, Micronesian, Amazonian, Aboriginal - that are in fact comprised of multiple individual cultures. The development of these macro cultural groups means that individual cultures must have interacted enough to either develop a shared set of cultural schemas, have been isolated from other members of its culture long enough to develop unique identities, or both. There is continual interand intra-cultural interaction within and across cultural boundaries. How should we consider cultural interactions within an SDI ensemble? If the cultural schemas involved in the interactions are largely similar, we would consider them to be intracultural. If the cultural schemas interactions are largely dissimilar, we would consider them to be intercultural. Identifying the boundaries between inter- and intracultural is not always clear or simple. 
Cultures can specialize and distribute particular forms of labor-cognitive labor in the form of knowledge and physical labor in the form of resource management-much like individuals. Cultural processes can facilitate both a distinct intracultural identity and set of schemas as well as an intercultural distribution of specialized labor and knowledge that makes the macro cultural grouping function more like a distributed system than a single entity. One example of this type of distributed and specialized macro grouping is the Tukano peoples of the Columbian Amazon, near the borders of Brazil, Peru and Venezuela. They are divided into about twenty groups. Each group has ties to a specific territory demarcated by rivers and each speaks a different, though related, language (Hugh-Jones 1993). The Tukanoans are often noted (by outsiders) by one of their marriage rules: a person should normally marry someone who speaks a different language. Each group traditionally manufactures specific types of artifacts, which stems from the regional distribution of particular resources.

The Tukano peoples share a common heritage. They consider themselves to be descended from the children of their Anaconda Ancestor. They were divided into a number of clans based on the birth order of their founding ancestors, the Imarimakana (the four sons of time), who placed rivers throughout their territory by cutting down trees that fell in the direction contrary to the direction of the river's flow (Forero Larrañaga 1999). These rivers separated the clans into 'territories' with differing distributions of resources. The Apaporis River, a large river that runs through Tukanoan territory, had been a tree situated at a waterfall named Yuisi. When Apaporis fell its roots got extended to the Caquetá, which had also been formed by a tree cut down. The branches of Apaporis made its tributaries:

Then the gods cut down the tree using a guard stick (macana). They made it fall and the Apaporis River was running towards the Caquetá River. The tree headed towards the north where the sun sets down, its higher branches laid down at Jirijirimo. There, they felled another tree to give continuity to the Apaporis. When that tree fell down it carried a vine we call Weria, forming the river Weriyaka that white people call Cananari..." (Fragment of a Myth related by Jaime Tanimuka, primary school teacher from Apaporis).

As the tree was being cut every splinter became a fish species. The smallest splinters were 'sardinas', 'sprats' (offspring of new species that would populate the river). The different trees, which were fell produced splinters that turned into the particular species of fish that now populates each river (Forero Larrañaga 1999).
The Tukano know that some species are present only in certain rivers or just at particular places along the course of a river. Generally a waterfall marks the limit for certain fish species. The giant catfish, lechero (Brachyplatystoma fylamentosum) or dorado (Pseudoplatystoma-flavicans), for example, cannot reach Jirijirimo. It only gets as far as Iañakopea waterfall, which marks the limit of the Tukanoan Territory in Apaporis.

The ancestral journey of the Tukanoan deities (or "heroes" as Forero Larrañaga describes them) is part of the shared Tukanoan mythology. In their cosmogony, the rivers as well as the rest of their territory were given to the people for a purpose. Mythology is reflected in everyday life where the world is conceived as being in a permanent state of change. Rather than receive gifts from their cultural mythological heroes, they received knowledge and instruction on how to respond to challenges. Each plant, animal and artifact has an essence that was acquired by the Imarimakana and placed as concrete beings throughout the Tukanoan territory. Each plant, animal and artifact has a spiritual owner who has the power to release the species he protects and manages, and does so when appropriately asked. The Imarimakana had to struggle and resolve problems in order to obtain the essences of all things, and the Tukanoan also face that same struggle as they manage resources, conflict and disease.

Like many other Amerindian groups, the Tukano place human beings within the environment rather than separate from it (Reichel-Dolmatoff 1996). The Tukano peoples record their history and their knowledge in association with their geography and environment. They employ a particularly sacred ritual around February of each year called March of the Manikins that speaks to the environmental management of their lands. The ritual narrative describes each of the species of plants and animals within "the world" in a specific sequence that mirrors a person traveling across the landscape. However, it also integrates several other socio-cultural dimensions: ecological, economic, sociopolitical, religious and aesthetic. The Tukanoans consider this ritual as essential to the "management of the world" (Forero Larrañaga 2002). An SDI that involved the Tukanoan peoples would not only need to be available in different languages for a Tukanoan macro cultural group, but it would also require the integration of their ritual that is essential to 'management of the world'.

\section{Conclusion}

Attempts to integrate indigenous and Western scientific (socalled 'realist') perspectives with respect to environmental management are not new. Ethnoscientists have promoted such integration for many years (Schultes 1991). Integra- 
tion of perspectives based on new experience, resulting in hybridization or adaptation, is not a new phenomenon. It is a natural mode of human understanding if we consider intrapersonal schemas to be an essential element in how that understanding is developed. When it comes to indigenous schemas that stand in high contrast to Western scientific ones, there is reluctance among the non-indigenous participants to accept the conceptual foundations of those schemas and the knowledge that flows from them (Stanner 1987). There is a tendency to manipulate rather than apprehend indigenous knowledge and refunctionalize it to serve the interests of the non-indigenous (Escobar 1998). The scientific community in general prefers to employ a Newspeak solution, especially when using information technologies to manage data, information and knowledge.

In looking at examples of indigenous narratives of geographic spaces and ecosystems, we find indigenous conceptualizations of space are not merely primitive understandings of space that are better explained by a scientific paradigm. They are ontologically different conceptualizations of 'reality'. Each culture creates its own legitimate forms of meaning. Individual cognition will focus on the features of space that are culturally, contextually and schematically meaningful. Conceptualizing space is so fundamental a phenomenon within our cognition, embedded at a preconceptual level, that we believe our personal conceptualizations of space to represent 'reality' as it truly is.

Cultural schemas are, in essence, our ontologies. They shape our ontological commitments to what exists in the world as well as the ways in which we approach and engage the world. And while they help structure our understanding of the world in which we are embedded, they are associative and flexible. They help to focus our attention to particular details of our experiences and give them salience. They allow us to make meaning of the contextualized, cultural experience in which we are always immersed. Formal ontologies constructed as taxonomic structures and categories of an objective world, however complex and inclusive of relationship axioms or aided by inferences, will not work across cultural boundaries because the cultural schemas rest on different ontological conceptualizations and commitments. Formal ontologies crystallize a single perspective into the ontology artifact as representative of what exists. They short-circuit the dialectic in which humans engage as part of their semantic negotiations about their ontological commitments.

An SDI is a shared socio-technological-informational ensemble that, if it is to be useful and successful for sustainability in the Amazon, must incorporate indigenous cultural schemas. Indigenous communities must have the ability to contribute to the collection of geospatial data and their contributions recognized as legitimate forms of knowledge. If the idea is to include the many cultures and communities in the construction of an SDI for the Amazon in order to come to mutually beneficial outcomes that are sustainable, then it is important to have an understanding of how cultural schemas function, how they are/can be created, blended and shared among our different information systems even when the schemas contradict each other. The informational contributions of others, whether derived scientifically or through VGI, must also be recognized as legitimate. In order for the SDI to work, it must include the larger cultural landscape to which cultural schemas can connect to the ready-to-hand elements of salient cultural experiences. Understanding the ready-to-hand elements upon which a conceptualization is based is the only way to understand its semantics. And while it may not be possible to instantaneously integrate the larger cultural landscape into our own schemas, it will facilitate the hermeneutic process of schema integration (i.e., learning) in which participants can begin to legitimate others' understanding of the same geospatial information and its relationship to sustainability for the Amazon.

Humans think and communicate in very flexible and schematic ways, and an SDI for the Amazon and associated information system ontologies should reflect this flexibility and the adaptive nature of human cognition in order to achieve semantic interoperability. In order to do so, we must forego the comfort of a rationalist worldview that presumes an objective external world as well as its logical opposite, solipsism. We need to reach beyond the lexical and syntactic in constructing machine ontologies that rely on symbol processing and extend their grounding to the phenomenological and hermeneuticembed within them the ability to negotiate meaning through a hermeneutic process of cultural schema integration. Casting culture as an emergent phenomenon, and cultural schemas as the complex networks of conceptualizations that comprise our ontologies, allows us to ground ontologies on a phenomenological footing.

\section{References}

Agre PE (1988) The dynamic structure of everyday life (MIT AI Technical Report, October 1988, No. 1085). MIT, Cambridge

Anderson RC, Spiro RJ, Montague WE (eds) (1984) Schooling and the acquisition of knowledge. Erlbaum, Hillsdale

Basso KH (1996) Wisdom sits in places. University of New Mexico Press.

Bateson G (1990) Mind and nature - a necessary unity. In: Sheldrake $\mathrm{R}$ (ed) The rebirth of nature. Century Books, London

Burenhult N, Levinson SC (2008) Language and landscape: a crosslinguistic perspective. Lang Sci 30(2-3):135-150

Câmara G, Fonseca F, Montiero AM, Onsrud H (2006) Networks of innovation and the establishment of a spatial data infrastructure in Brazil. Inf Technol Dev 12(4):255-272

Cane S (2002) Pila Nguru: The Spinifex people. Fremantle Art Centre, North Fremantle 
Carrick J (ca. 1980) The Australian aboriginal origins and art: A very brief orientation [Electronic Version]. One World Magazine. Retrieved August 9, 2001 from http://www.oneworldmagazine. org/gallery/abo/intro.html

Casey ES (1996) How to get from space to place in a fairly short stretch of time: Phenomenological prolegomena. In: Feld S, Basso KH (eds) Senses of place. School of American Research, Santa Fe, pp 13-52

Cerbone DR (2008) Heidegger: A guide for the perplexed. Continuum International, London

Chandrasekaran B, Josephson JR, Benjamins VR (1999) What are ontologies, and why do we need them? IEEE Intell Syst Their Appl 14(1):20-26 [see also IEEE Intelligent Systems]

Christensen CB (2007) What are the Categories in Sein und Zeit? Brandom on Heidegger on Zuhandenheit. Eur J Philos 15 (2):159-185

Craglia M, Goodchild MF, Annoni A, Câmara G, Gould M, Kuhn W et al (2008) Next-Generation Digital Earth. International Journal of Spatial Data Infrastructures Research 3:146-167

D'Andrade R (1995) The development of cognitive anthropology. Cambridge University Press, Cambridge

Davis PM (1991) Cognition and learning: A review of the literature with reference to ethnolinguistic minorities. Summer Institute of Linguistics, Dallas

Davis CA Jr, Fonseca FT, Câmara G (2009) Beyond SDI: Integrating science and communities to create environmental policies for the sustainability of the Amazon. International Journal of Spatial Data Infrastructures Research 4:156-174

DiMaggio P (1997) Culture and cognition. Annu Rev Sociology $23: 263-288$

Dreyfus H (2007) Why Heideggerian AI failed and how fixing it would require making it more Heideggerian. Artif Intell 171 (18): $1137-1160$

Escobar A (1998) Whose knowledge, whose nature? Biodiversity, Conservation and the Political Ecology of Social Movements. Journal of Political Ecology 5

Fonseca F, Martin J (2005) Play as the way out of the newspeaktower of Babel dilemma in data modeling. Paper presented at the twenty-sixth international conference on information systems: philosophy and research methods in information systems, 2005

Forero Larrañaga O (1999) The March of the Manikins: Agroforestry practices and spiritual dancing in Northwest Amazonia. Paper presented at the PILAS Annual Conference, University of Hull, Hull

Forero Larrañaga O (2002) Indigenous knowledge and the scientific mind: Activism or colonialism? Paper presented at the conference on conservation and sustainable development-comparative perspectives, Yale University, New Haven

Freeman WJ (1991) The physiology of perception. Scientific American 242

Freeman WJ (1995) Societies of brains: A study in the neuroscience of love and hate, the Spinoza lectures, Amsterdam, The Netherlands, (Vol 59). Erlbaum, Hillsdale

Gruber TR (1993) Toward principles for the design of ontologies used for knowledge sharing. In: Guarino N, Poli R (eds) Formal ontology conceptual analysis and knowledge representation. Kluwer Academic

Guarino N (1998) Formal ontology and information systems. Paper presented at the conference name|. Retrieved Access Date|. from URL|

Gupta A, Ferguson J (eds) (1997) Culture, power, place: Explorations in critical anthropology. Duke University Press, Durham

Heidegger M (1927) Being and time (J. Macquarrie, E. Robinson, 1962 trans. ed). Harper and Row, New York
Hugh-Jones S (1993) Clear Descent or Ambiguous Houses? A ReExamination of Tukanoan Social Organisation. L'Homme 33 (126-128):95-120

Lawlor R (1991) Voices of the first day: Awakening in the aboriginal dreamtime. Inner Traditions, Rochester

Majid A, Bowerman M, Kita S, Haun DMB, Levinson SC (2004) Can language restructure cognition? The case for space. Trends Cogn Sci 8(3):108-114

Mark DM, Turk AG (2003a) Ethnophysiography. Paper presented at the Pre-COSIT Workshop

Mark DM, Turk AG (2003b). Landscape categories in Yindjibarndi: ontology, environment, and language. Paper presented at the Spatial Information Theory: Foundations of Geographic Information Science, International Conference, COSIT 2003, Kartause Ittingen, September 24-28, 2003

Mark DM, Turk AG, Stea D (2007) Progress on Yindjibarndi Ethnophysiography. In: Spatial information theory, pp 1-19

Rajabifard A, Williamson IP (2001) Spatial data infrastructures: Concept, SDI hierarchy and future directions. Paper presented at the GEOMATICS ' 80 Conference, 29 April-2 May, 2001, Tehran

Rajabifard A, Feeney M, Williamson IP (2002) The cultural aspects of sharing and dynamic partnerships within an SDI hierarchy. Cartogr J 31(1)

Reichel-Dolmatoff G (1996) The forest within. The world view of the Tukanoan Amazonian Indians. Themis Books, Devon

Rosaldo R (1993) Culture and Truth: The remaking of social analysis. Beacon, Boston

Rumelhart DE, McClelland JL (1986) Parallel distributed processing: Exploration in the microstructure of cognition, Vols. 1 \& 2. In: Psychological and biological models (Vol. 1 \& 2). Cambridge: MIT.

Saab DJ (2003) Conceptualizing space: Mapping schemas as meaningful representations. Unpublished Master's Thesis, Lesley University, Cambridge, MA, http://www.djsaab.info/thesis/djsaab thesis.pdf

Saab DJ, Fonseca F (2008) Ontological complexity and human culture. Paper presented at the philosophy's relevance in information science, Paderborn

Schultes RE (1991) Ethnobotany and technology in the Northwest Amazon; Example of partnership. Environ Conserv 18(3)

Smith B (1995) Formal ontology, common sense and cognitive science. Int J Hum Comput Stud 5-6:641-667

Smith B (2003) Ontology. In: Floridi L (ed) Blackwell's guide to philosophy of computing and information. Blackwell, Oxford, pp $155-166$

Smith B, Ceusters W, Klagges B, Köhler J, Kumar A, Lomax J et al. (2005) Relations in biomedical ontologies. Genome Biol 6(5)

Sowa J (1999) Knowledge representation: Logical, philosophical, and computational foundations. Brooks Cole, Pacific Grove

Stanner WEH (1987) The dreaming. In: Edwards WH (ed) Traditional aboriginal society. Macmillan, Melbourne, pp 225-236

Strauss C, Quinn N (1997) A cognitive theory of cultural meaning. Cambridge University Press, Cambridge

Talmy L (2001) The cognitive culture system. Monist 78(1)

Uschold M (2003) Where are the semantics in the semantic web? AI Mag 24:25-36 Fall 2003

Watson-Verran H, Turnbull D (1995) Science and other indigenous knowledge systems. In: Jasanoff S, Markle GE, Petersen JC, Pinch T (eds) Handbook of science and technology studies. Sage, Thousand Oaks, pp 115-139

Wilson D (1998) Ontological pluralism and information systems research. Paper presented at the PAIS II, the Second Symposium and Workshop on Philosophical Aspects of Information Systems: Methodology, Theory, Practice and Critique, University of the West of England, Bristol, July 27-29, 1998

Winograd T, Flores F (1987) Understanding computers and cognition: A new foundation for design. Addison-Wesley, Boston 